\title{
ELECTRONIC MEASUREMENT OF ICE VELOCITY
}

\author{
By A. E. Harrison \\ (Department of Electrical Engineering, University of Washington, Seattle, Washington 98105, \\ U.S.A.) \\ and DAvid LeE \\ (Hewlett Packard Company, P.O. Box 301, Loveland, Colorado 80537, U.S.A.)
}

\begin{abstract}
Aвstract. A light-weight solid-state electronic distance meter was used to measure short-term ice velocities during a two-day interval on the Coleman Glacier at Mt Baker, Washington, U.S.A. The velocities fluctuated rapidly from zero or almost zero to a large fraction of a meter per day. There was little or no correlation between the movement at different stations and the fluctuations masked any diurnal variation if such existed. The ease of obtaining the results demonstrates the utility of the new equipment for extending the possibilities of glaciological research.

RÉsumé. Mesures électroniques de la vitesse de la glace. Un mètre électronique, matériel de faible poids, a été utilisé pour mesurer les vitesses de la glace pendant de courtes périodes, à des intervalles de deux jours sur le Coleman Glacier au Mt Baker, Washington, U.S.A. La vitesse fluctue rapidement depuis zero ou presque zero jusqu'à une large fraction de mètre par jour. On a trouvé un lien très faible ou nul entre les mouvements à différentes stations, et les fluctuations masquent une éventuelle variation diurne si elle existe. La facilité avec laquelle ont été obtenus ces résultats montre l'utilité de ce nouvel équipement pour étendre les possibilités de la recherche glaciologique.

Zusammenfassung. Elektronische Messung der Eisgeschwindigkeit. Ein leichtes, solides elektronisches Entfernungsmessgerät wurde zur Bestimmung kurzperiodischer Eisgeschwindigkeiten innerhalb eines Zeitraumes von zwei Tagen am Coleman Glacier am Mt Baker, Washington, U.S.A., verwendet. Die Geschwindigkeiten schwankten schnell von Null oder fast Null bis nahezu einen Meter pro Tag. Es bestand Geschwindigkeiten schwankten schnell von Null oder ast Nuls bersiedenen Stationen und die Schwankungen geringe oder keine Bezichung überdeckten jede tägliche Variation, können, zeigt, wie gut die neue Ausrüstung zur Ausweitung der Möglichkeiten in der glaziologischen Forschung geeignet ist.
\end{abstract}

Measurement of ice velocities by conventional surveying techniques has been so tedious and time-consuming that it has often been neglected, even when the need for the information was obvious. The availability of solid-state electronic distance-measuring equipment offers a new approach to measuring velocities. A program to demonstrate the advantages of electronic instrumentation was initiated and the results indicate that the original enthusiasm for the method is justified. Although the program was intended to demonstrate the utility of the method and gain experience with the equipment in the field, useful data on the behavior of moving ice were also obtained.

The Coleman Glacier on the north-west slope of Mt Baker in the state of Washington was chosen for these tests. The response of this glacier to climatic fluctuations in the last two decades has been described by Bengtson (1956) and Harrison (196r[a], ig6r[b], i97o). The glacier front is now essentially stationary, indicating that the rate of flow has decreased from its maximum when the glacier was actively advancing but is still adequate to supply the losses by melting. The glacier had advanced a few meters during the i $969-70$ winter, overriding its 1969 terminal moraine. The thickness at the front decreased noticeably during the warm summer of 1970 but the retreat from the previous winter maximum position was estimated as less than $3 \mathrm{~m}$.

Ice velocities were measured at three ice stations with a Hewlett-Packard Model $3800 \mathrm{~A}$ Distance Meter. This instrument utilizes the non-coherent near-infrared radiation from a gallium-arsenide diode to measure distance electronically. It is shown in operation at $\mathrm{Mt}$ Baker in Figure $\mathrm{I}$. The weight of the instrument is $7.7 \mathrm{~kg}$, the power supply unit weighs $5.9 \mathrm{~kg}$ and a lightweight tripod, designed for use in mountain terrain, weighs $4.3 \mathrm{~kg}$. The instrument has a range of $1.2 \mathrm{~km}$ using a single Geodimeter reflector, $9 \times 10 \mathrm{~cm}$, weighing 
$0.4 \mathrm{~kg}$. With a three-reflector unit, $\mathrm{I}_{5} \times \mathrm{I} 6 \mathrm{~cm}$, weighing $\mathrm{I} . \mathrm{I} \mathrm{kg}$, the range is $3.0 \mathrm{~km}$. The instrument has a resolution of $0.6 \mathrm{~mm}$ and errors of $\pm 3 \mathrm{~mm}$ plus one part in 100 ooo. This sum represents a total error of $\pm \mathrm{I} .4 \mathrm{~cm}$ for station $\mathrm{BUFF}$, the most distant ice station. When changes in distance are involved, as in velocity measurements, the absolute accuracy is not a limitation and a relative error of about $\pm 3 \mathrm{~mm}$ is possible. The time interval between distance measurements was generally two hours or more, so the error in short-term ice velocity would be about $\pm 36 \mathrm{~mm}$ per day. The number of measurements was considered too small to warrant a statistical treatment of error.

Distance measurements are indicated by a digital readout after a manual adjustment to obtain a null reading. Correction for the effect of atmospheric conditions on the propagation velocity of infrared light is accomplished by a control which adjusts the timing frequency to the correct value for the atmospheric pressure and temperature at the time of measurement.

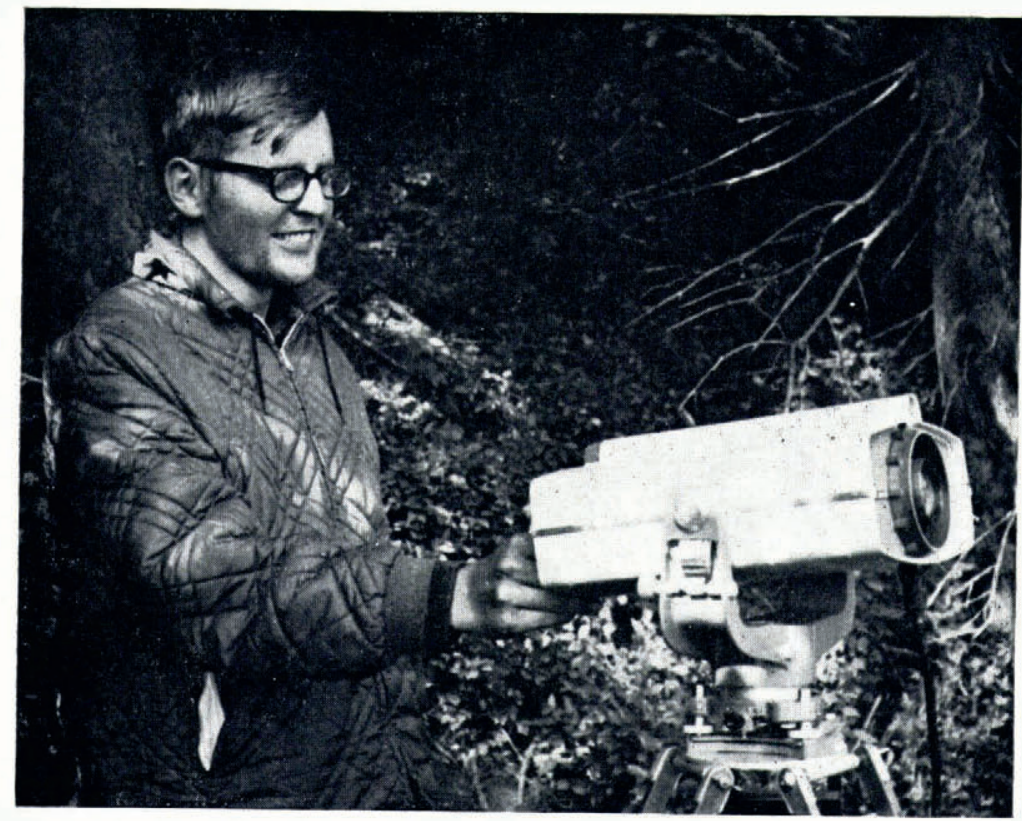

Fig. I. David Lee operating the Model 3800 A Distance Meter at Mt Baker.

A one degree change in temperature causes a change of +0.85 parts per million, or $+0.85 \mathrm{~mm}$ in a one $\mathrm{km}$ path. A Io mbar change in pressure causes a change of -2.8 parts per million. These values are for the atmospheric conditions at the distance-measuring station $\left(10^{\circ} \mathrm{C}\right.$ and $860 \mathrm{mbar}$ ) and the corrections vary for other atmospheric conditions. The effect of variations in humidity is considered negligible in optical and near-infrared systems, and it is included in the variations for temperature and pressure.

The distance to a fixed station $(\mathrm{T})$ on bedrock near the ice tongue, shown in Figure 2, was monitored as a check on the reliability of the atmospheric corrections. The measured distance to this station is plotted in Figure 3 to a greatly expanded scale. Neglecting the last value measured at og.r $2 \mathrm{~h}$ on 3 August 1970, when the battery was discharged, the mean distance was $640.4486 \mathrm{~m}$ and measured values ranged from 640.444 to $640.45^{2} \mathrm{~m}$. These variations might be explained by experimental error, by atmospheric conditions differing along the path or by instrumental errors. A discharged battery is known to have caused the 
large error in the last measurement and there is some uncertainty regarding the battery voltage during the two previous readings. Measurements of the comparison path suggest that the error estimated above is justified, and the results indicate that the use of a comparison path was probably not essential. The maximum variation from the mean value was $4.6 \mathrm{~mm}$ and the variation was generally less than $3.0 \mathrm{~mm}$. The total motion of the ice stations (Fig. 4) is quite large and the velocity fluctuations are much greater than the probable error.

The locations of the three ice stations used to determine the velocity are also indicated on the photograph of Coleman Glacier in Figure 2. BUFF station is at the base of the upper ice

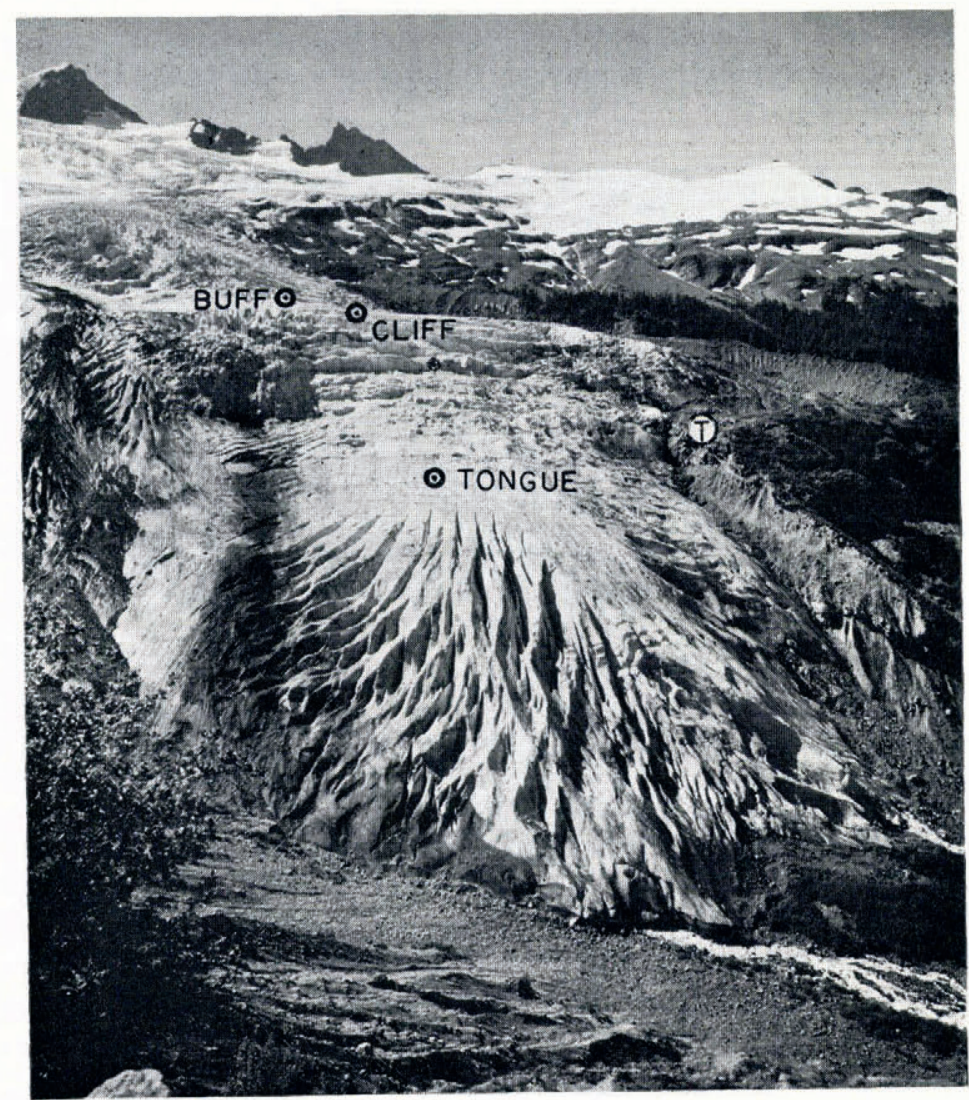

Fig. 2. Photograph of Coleman Glacier on Mt Baker from the distance-measuring station (DIME), showing the location of the three ice stations, BUFF, CLIFF and TONGUE, and the bedrock reference station $T$.

fall at a distance initially of $\mathrm{I}$ I $30 \mathrm{~m}$. CLIFF station is slightly behind the top of the lower ice fall at a distance of $893 \mathrm{~m}$. TONGUE station was installed a day later in the smooth region between the lower ice fall and the splaying crevasses above the terminus, at a distance of $573 \mathrm{~m}$. These ice stations were placed as far as possible from submerged bedrock cliffs, which were known to be under the serac areas to the left of stations BUFF and CLIFF, in order to avoid uneven flow. They were located as close as possible to the center of the glacier and the region of maximum flow. The final choice of target locations was dictated by visibility from the distance-measuring station (DIME) located on an old moraine on the opposite side of the canyon at a point almost in line with the direction of flow. The distances observed were 


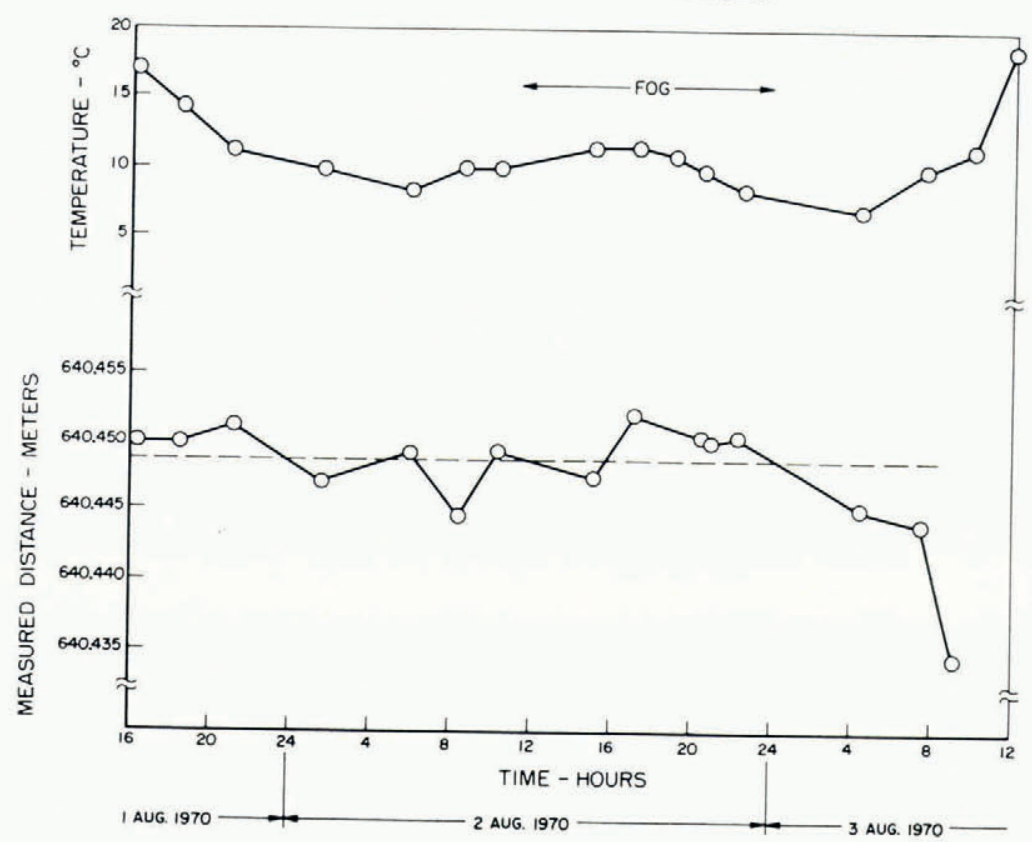

Fig. 3. Measured distance to a fixed target at station $T$ and temperature at the distance-measuring station, plotted as a function of time. The average of the readings is shown as a pecked line.

radial distances from DIME station and are plotted as displacements in Figure 4. The data for each ice station are labeled with an approximate initial distance as a reminder that the three curves have been superimposed. Short-term radial velocities were corrected by dividing the rate of displacement by the product of the cosines of the horizontal and vertical angles between the line of sight and the estimated direction of flow. Vertical angles were measured at DIME station with a Wild T-2 theodolite. Surface slope angles and direction of flow were estimated in the field by the ice teams which installed the cube-corner reflectors used as

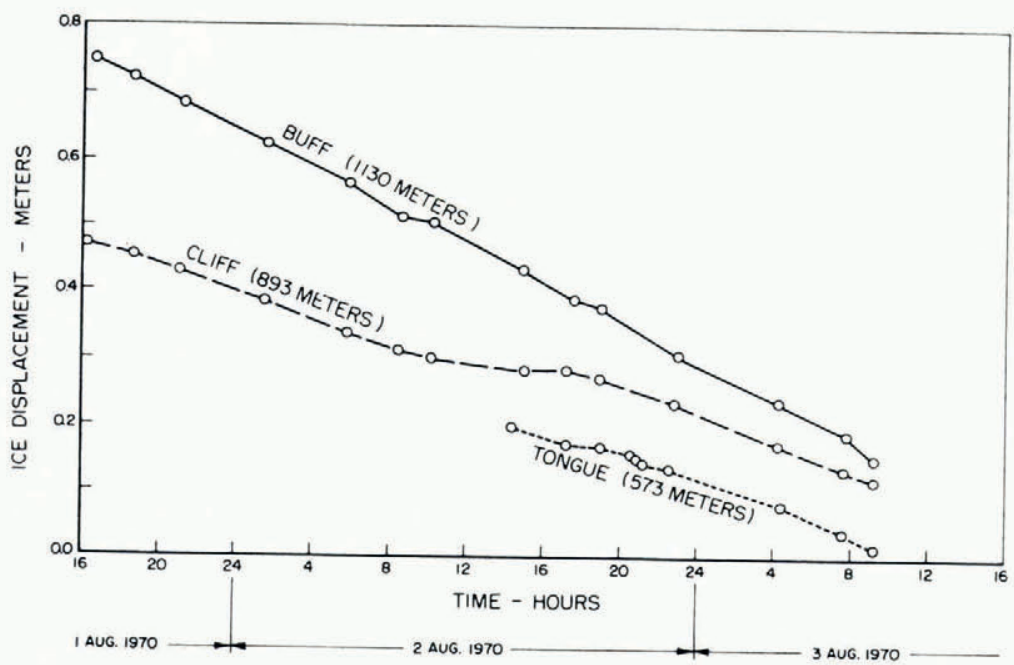

Fig. 4. Radial displacements of the three ice stations as a function of time, superimposed on an arbitrary distance scale. 
targets. Their estimates agreed within a few degrees with estimates based on a r965 topographic map. Since the program was intended primarily as a demonstration of the method, an error of several per cent was not considered serious.

Corrected short-term velocities plotted for the average time for each interval are shown in Figure 5. Temperature at the measuring station is also shown as a function of time. For most measurements, the velocities are several times greater than the observing errors and the fluctuations indicate that the ice movement was quite spasmodic. The magnitude of the fluctuations masks any correlation between velocity and temperature or time, if any correlation exists. The average velocities over the entire period for each ice station are indicated by horizontal lines at the right side of Figure 5. These values show the expected decrease in velocity as the ice moves down the glacier and agree with previous unpublished estimates of

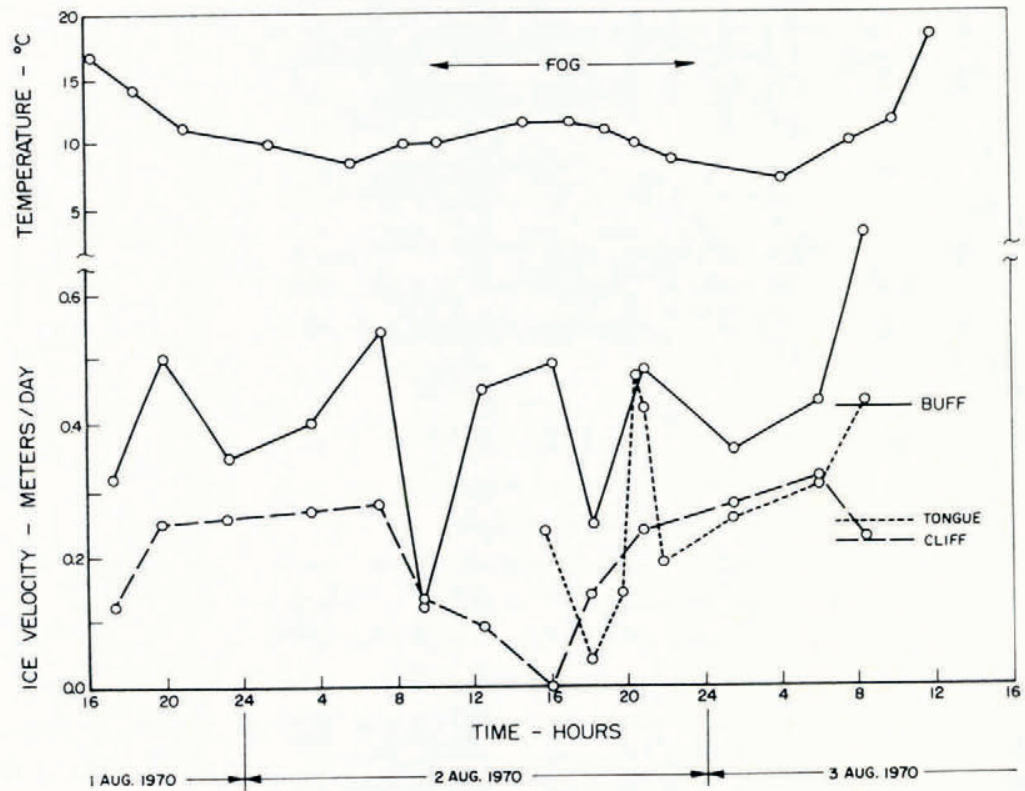

Fig. 5. Corrected ice flow velocities at the three stations, and temperature at the distance-measuring station, plotted as a function of time. Average velocities are shown on the right and identify the curves for each station.

the velocity. Comparison of Figures 4 and 5 emphasize that the fluctuations are much less apparent when plotted as displacements. The movement appears reasonably continuous in Figure 4, although the points are connected by straight lines. The lines connecting the velocity data in Figure 5 have no relation to the instantaneous velocities, which must have been both greater and less than the values averaged over discrete intervals. The spasmodic nature of the ice movement was even greater than indicated by Figure 5 .

There may be a correlation between the times of minimum velocity suggested by the daytime data on 2 August 1970. However, the distance between BUFF and CLIFF stations is $273 \mathrm{~m}$, somewhat less than the $320 \mathrm{~m}$ between CLIFF and TONGUE, and the time intervals of $7 \mathrm{~h}$ and $2 \mathrm{~h}$ between observed minimum velocities at the three stations are probably unrelated. It seems likely that any apparent correlation between the times of minimum velocity is a coincidence. TONGUE station was presumed to be located in an area of shear planes. The behavior of TONGUE station, which spurted forward after moving only 
$3 \mathrm{~mm}$ during a two-hour interval, could be explained by a decreased velocity while the shear plane under it did not slide, followed by a sudden forward movement for half an hour. This sudden movement was discovered by accident. Lack of credibility in the data led to additional measurements at the time which verified that the rapid motion was continuing. Fog conditions prevented the observation of the other stations during this interval. Considerably more data at a greater number of points in the same area and over a longer period of time would be required to verify this hypothesis.

The failure of CLIFF station to make any movement between $15.00 \mathrm{~h}$ and $17.12 \mathrm{~h}$ on 2 August 1970 could have several explanations. The reflector was mounted atop a $2 \mathrm{~m}$ tripod. Uneven melting of the stakes supporting the tripod could have occurred, causing the tripod to tilt backward sufficiently to cancel the forward motion. There was no evidence indicating that this tripod was unstable and it was reasonably solid when the reflector was removed the next day. The entire ice block on which CLIFF station was mounted could have remained stationary for two hours, although that explanation seems unlikely. It seems more probable that this ice block could be tilting backward as it moved toward the brink of the lower ice fall, due to the slope of the bedrock behind the cliff. The two motions could have been equal and opposite for a short time. This third explanation could also account for the smaller average velocity for CLIFF station mentioned earlier.

Several conclusions are obvious from the results of these brief tests. The advantages expected from electronic distance-measuring equipment were demonstrated. The technique is ideal for detecting and measuring short-term fluctuations in ice flow. Considerable data can be obtained quite easily with a distance meter alone. The combination of a distance meter with a theodolite would simplify making a study of the complete velocity field for a glacier.

This enthusiasm for the new technique must be tempered by the realization that it does not solve many of the problems involved in an extended long-term study of flow velocity. It merely provides a convenient method for obtaining more data on short-term average velocities. The difficulties common to all methods of measuring ice velocity remain. Any comprehensive study will require a tremendous number of ice stations, spaced laterally as well as longitudinally, and these stations must be measured frequently. The number of instruments and operators becomes prodigious if short-term measurements are contemplated. The problem of stabilizing many stations over a long period of time is not simple. The tripods used at Mt Baker in these tests were not stabilized and collapsed in less than ten days. Placing and maintaining corner reflectors in crevassed areas remains an unsolved but probably not an insurmountable problem. Avoiding the measurement of glaciers with rough terrain is certainly not the answer. It is the behavior of these "difficult" glaciers that may lead to an understanding of the complex phenomena of glacier flow. Electronic surveying techniques provide a tool that should simplify the collection of the data that are needed.

\section{MS. received 9 December 1970 and in revised form I 8 April 197 I}

\section{REFERENCES}

Bengtson, K. B. 1956. Activity of the Coleman Glacier, Mt. Baker, Washington, U.S.A., 1949-1955. Fournal of Glaciology, Vol. 2, No. 20, p. 708, $710-13$.

Harrison, A. E. I961[a]. Fluctuations of the Coleman Glacier, Mt. Baker, Washington. Fournal of Geophysical Research, Vol. 66, No. 2, p. 649-50.

Harrison, A. E. $1961[\mathrm{~b}]$. Ice thickness variations at an advancing front, Coleman Glacier, Mt. Baker, Washington. Journal of Glaciolsgy, Vol. 3, No. 30, p. 1 i 68 -70. [Letter.]

Harrison, A. E. 1970. Fluctuations of Coleman Glacier, Mt Baker, Washington, U.S.A. Fournal of Glaciology, Vol. 9 , No. 57 , p. $393-96$. 